\title{
Ortodontik Tedavi Sırasında Beyaz Nokta Lezyon Oluşumu
}

\author{
Mehmet Akın(0000-0003-0776-7653) ${ }^{\alpha}$, Faruk Ayhan Başçiftçi(0000-0002-6865-4719) ${ }^{\beta}$
}

Selcuk Dent J, 2021; 8: 45-49 (Doi: 10.15311/selcukdentj.855661)

Basvuru Tarihi: 07 Ocak 2021 Yayına Kabul Tarihi: 25 Ocak 2021

Öz

\section{Ortodontik Tedavi Sırasında Beyaz Nokta Lezyon Oluşumu}

Amaç: Sabit ortodontik tedavi sırasında oluşabilen beyaz nokta lezyonlar bazen tedavi sonrasında da ciddi problemler oluşturmaya devam etmektedir. Bu çalışmanın amacı sabit ortodontik tedavi sırasında oluşan beyaz nokta lezyonların dağılımını değerlendirmektir.

Gereç ve Yöntemler: Çalışmaya en az bir dişinde beyaz nokta lezyon bulunan 145 hasta (58 kız 87 erkek, 11.8-17 yaş aralığında) çalışmaya dahil edilmiştir. Tedavi öncesinde ve sonrasında alınan fotoğraf kayıtları değerlendirilerek etkilenen dişler tespit edilmiştir. Elde edilen veriler Ki-Kare testi kullanılarak analiz edilmiştir.

Bulgular: Erkeklerde, kızlarda ve genel olarak dağılım incelemesinde sağ sol arasında farklılık görünmezken, üst çene alt çeneye göre daha fazla yoğunlukta beyaz nokta lezyon göstermektedir. Dişsel olarak bakıldığı zaman en fazla etkilenen dişin sağ üst yan keser diş olduğu belirlenmiştir $(\% 93,71)$.

Sonuç: Beyaz nokta lezyon ağız hijyenine bağlı olarak tutucu alanlarda oluşabilmektedir.

\section{ANAHTAR KELIMELER}

Ortodontik tedavi, Ağız hijyeni, Beyaz nokta lezyonlar

Diş çürüğü, diş hekimliğinin en yaygın görülen hastalıklarından birisidir. Çürük oluşumu dişin en dış kısmı olan mine tabakasından bağlar. Mine çürüğü erken dönemde klinik olarak diş rengine göre saydamlığını kaybetmiş ve belirgin bir opak beyaz lezyon olarak görünmektedir. Sabit ortodontik tedavinin mine yüzeyindeki demineralizasyonu arttırdığı uzun yıllardır bilinmektedir. ${ }^{1}$ Sabit ortodontik tedaviler özellikle ağız hijyeni kötü olan bireylerde, diş yüzeyinde dental plak birikimini arttırıp, bakteriyel florayı etkileyerek fakültatif bakteriyel populasyonu arttırmaktadır.2,3

Ortodontik tedavilerde beyaz nokta lezyonlar ağız hijyeninin kötü olduğu bireylerde sıklıkla görülür. Klinik olarak mine dekalsifikasyonlarının belirlendiği bölge bakterilerin uzun süre kalabileceği ve temizlemenin güç olduğu bölgelerdir. Bu bölgelerde hem demineralizasyonun daha çok oluşmasına bağlı olarak, hem de plak remineralizasyon oluşmasına engel olduğu için beyaz nokta lezyonlar ortaya çıkar.,4 Ortodontik bant, braket veya daha karmaşık tedavi seçenekleri hem ağızda plak için tutucu alan

\section{ABSTRACT}

White Spot Lesion Formation During Orthodontic Treatment

Background: White spot lesions that may occur during fixed orthodontic treatment sometimes continue to cause serious problems after treatment. The aim of this study is to evaluate the distribution of white spot lesions that occur during fixed orthodontic treatment.

Methods: 145 patients ( 58 females, 87 males, between the ages of 11.8 and 17 years) with white spot lesions in at least one female were included in the study. The affected teeth were identified by evaluating the photographs taken before and after the treatment. The data obtained were analyzed using the ChiSquare test.

Results: While there is no difference between right and left in males, females and in general distribution analysis, the upper jaw shows more intensity white spot lesions than the lower jaw. When examined dentally, it was determined that the most affected tooth was the right upper lateral incisor (93.71\%).

Conclusion: White spot lesion can occur in retaining areas depending on oral hygiene.

\section{KEYWORDS}

Orthodontic treatment, Oral hygine, White spot lesions

oluşturmakta hem de tutunan bu plakların doğal yolla uzaklaştırılmasında rol oynayan kas ve tükürük faaliyetlerine engel olmaktadır. ${ }^{5} \mathrm{Bu}$ sirkulasyonda fermente karbonhidrat intiva eden düşük pH daki plak oluşur. Bu plak birikmini ve olgunlaşmasını hızlandırır. Ayrıca Streptococcus mutans ve lactobacilli gibi asidik bakteri kolonizasyonunu oluşumunu da arttırır. ${ }^{4-8}$

Genel olarak ortodonti hasta grubunda ortodonti hastası olmayan gruba göre daha sık beyaz nokta lezyon görülmektedir ve bu lezyonlar tedaviden yıllar sonra da estetik problemler oluşturmaktadır.9 Ortodonti hastalarının beyaz nokta lezyon prevelansı açısından yapılan çalışmalarda hastaların \% 2 ile \% 96 arasında beyaz nokta lezyona sahip olduğu değişik araştırmacılar tarafından tespit edilmiştir., ${ }^{1,4,10,11}$ Dağılımın bu kadar geniş olmasının sebebi demineralizasyonu belirleme yönteminin farklılığı, skorlanma tipi, daha önce demineralizasyon varlığı, kullanılan malzemelerin 11 çeşitliliği olabilir. Genç hastalar değişik sebeplerden dolayı daha fazla risk altındadırlar.11

\footnotetext{
${ }^{\alpha}$ Alanya Alaaddin Keykubat Üniversitesi, Diş Hekimliği Fakültesi, Ortodonti AD, Antalya, Türkiye

$\beta$ Özel Klinik, Konya, Türkiye
} 
Ağız ortamında normalde dişlerin yüzeyinde demineralizasyon ve remineralizasyon döngüsü devam etmektedir. Bu yüzden dişler yüzeyinde doku bütünlüğü devam eder ama ortodontik tedavi sırasında ortodontik bantlar ve braketler demineralizasyonun artmasına ve remineralizasyonun engellenmesine sebep olurlar. Bu çalışmada da ortodontik tedavi sırasında oluşan beyaz nokta lezyonların hangi dişleri daha çok etkilediğinin tespit edilmesi amaçlanmıştır.

\section{BIREYLER VE YÖNTEM}

Çalışma grubumuz Selçuk Üniversitesi Diş Hekimliği Fakültesi, Ortodonti Anabilim Dalı kliniğinde tedavisi bitirilen, tedavi bitirilme yaşları 11,8-17 arasında olan ve bu çalışma için ailesi ve kendisi istekli olan olgulardan oluşturulmuştur. Bu çalışma için Konya Necmettin Erbakan Üniversitesi Meram Tıp Fakültesi Etik Kurul Başkanlığından Etik Kurul Kararı alınmıştır (2009-90). Hasta ve hasta yakınları beyaz nokta lezyonların ne olduğu, nasıl oluştuğu, çalışma sırasında yürütülecek tedaviler ve kontrol grubu hakkında bilgilendirilip hangi tedavi grubuna veya kontrol grubuna dâhil edilecekleri kendi isteklerine göre belirlenerek onayları alınıp çalışmaya dâhil edilmişlerdir.

Çalışmaya aşağıdaki kriterlere uyan hastalar dâhil edilmiştir;

1. En az 1 yıl süresince aktif sabit ortodontik tedavi görmüş olmak,

2. Sigara içme alışkanlığı olmaması,

3. Daha önce herhangi bir beyaz nokta lezyon tedavisi görmemiş olması,

4. Daha önce beyazlatma tedavisi uygulanmamış olması,

5. Plak birikimine bağlı olarak ileri derecede dişeti rahatsızlığı ve ödemle seyreden iltihabi dişeti rahatsızlıklarının bulunmaması,

6. Etkilenen dişlerin içsel ve dışsal lekelenmeye ve anatomik veya morfolojik yapı bozukluğuna sahip olmaması.

Ağzında en az bir tane beyaz nokta lezyon bulunan 145 hasta çalışmaya dâhil edilmiştir.

Beyaz nokta lezyonları bulunan, ortodontik tedavi bitirilen, kendilerine beyaz nokta lezyonlar hakkında bilgi verilen ve çalışmaya dâhil olmak isteyen hastalardan Beyaz nokta lezyon sınıflaması yapmak için fotoğraf kayıtları alınmıştır. Görüntüler hasta diş hekimi koltuğunda sırtüstü yatar pozisyonda iken koltuğun konumu $70^{\circ}$ konumunda hasta rahat bir pozisyonda ağız ekartörler yardımı ile açıkken alınmıştır.

Ağız içi muayenesinde diş yüzeyleri kurutularak dişler tek tek gözle değerlendirilip beyaz nokta lezyon varlığı açısından incelenmiştir. Beyaz nokta lezyon varlığı tespit edilen dislerin tek tek fotoărafları alınmıstır.
Fotoğrafların alınmasında daha yakından görüntü alabilmek için makro objektif (Micro-Nikkor 105 mm; Nikon Corporation, Tokyo Japan) bulunan digital fotoğraf makinası kullanılmıştır (Nikon D 80; Nikon Corporation, Tokyo, Japan). Işının görüntü üzerinde gölge yapmasını engellemek, fotoğrafı çekilen dişlerin aydınlatılmasının dişin her bölgesinde aynı olmasını sağlamak için ring flaş (Sigma EM 140 DG; Sigma Corporation, New York, USA) kullanılmıştır. Çekilen fotoğraflarda dişleri aydınlatmada kullanılan flaştan güçlü, ışınların dişten yansıması sırasında fazla görüntü parlamasını engelleyerek daha net görüntü elde etmek için kros polarize filtre kullanılmıştır.

Bu dişler başlangıç kayıtlarına göre Curzon veSpector12 tarif ettiği şekilde etkilenme derecelerine göre üç sınıfa ayrılmıştır;

\section{Sınıf 0: Lezyonun görünmediği durumlar}

Sınıf 1: Lezyonun genişliğinin dişin ön yüzeyinin 1/3، üne kadar olan kısmını kapsadığı durumlar,

Sınıf 2: Lezyonun genişliğinin dişin ön yüzeyinin 1/3‘ü ile 2/3، ü arasında bir bölgeyi kapsadığı durumlar,

Sınıf 3: Lezyonun genişliğinin dişin ön yüzeyinin $2 / 3$ ‘ ünü aştığı durumlar.

Lezyonlarının dağılımının istatistiksel olarak belirlenmesi sayımla elde edilen bir çalışma olduğu için Windows ortamında SPSS istatistik paket programından (SPSS Inc. version 17.0) yararlanarak Ki-Kare testi uygulanarak belirlenmiştir.

\section{BULGULAR}

Çalışmada 58 kız 87 erkek hasta olmak üzere toplam 145 hastaya ait 3356 adet diş değerlendirilmiştir. Dişlere ait fotoğrafların hepsi bilgisayar ortamına aktarılarak incelenmiştir. İncelemenin sonucunda 1769 adet etkilenmiş diş tespit edilmiştir. Etkilenen dişler AutoCAD 2011 programında çizilerek değerlendirilmiştir. Beyaz nokta lezyonların dağılımı Çizelge 1'de gösterilmektedir.

Beyaz nokta lezyonların dişler arası dağılımı hem sınıflama yapmadan hem de sıniflamadan sonra erkekler arasında, kızlar arasında ve cinsiyet ayrım yapmaksızın genel olarak Ki-Kare uygunluk testiyle yapılan incelemede farklılık göstermektedir. Erkeklerde, kızlarda ve cinsiyet ayırımı yapmadan yapılan dağılım incelemesinde sağ sol arasında farklılık görünmezken, üst çene alt çeneye göre daha fazla yoğunlukta beyaz nokta lezyon göstermektedir. Dişsel olarak bakıldığı zaman en fazla etkilenen dişin sağ üst yan keser diş olduğu belirlenmiştir $(\% 93,71)$. 


\section{Çizelge 1.}

\section{Beyaz Nokta Lezyonların Dağılımı}

\begin{tabular}{|c|c|c|c|c|c|c|c|c|c|c|c|c|c|c|c|c|c|c|c|c|c|c|c|c|c|c|}
\hline & 16 & 15 & 14 & 13 & 12 & 11 & 21 & 22 & 23 & 24 & 25 & 26 & 36 & 35 & 34 & 33 & 32 & 31 & 41 & 42 & 43 & 44 & 45 & 46 & TOPLAM & SONUÇ \\
\hline Erkeklerin Diş Sayıs & 58 & 42 & 58 & 58 & 56 & 58 & 58 & 57 & 58 & 58 & 45 & 58 & 58 & 50 & 58 & 58 & 58 & 58 & 58 & 58 & 58 & 58 & 52 & 58 & 1346 & \\
\hline Kıdarın Diş Sayısı & 87 & 58 & 87 & 87 & 87 & 87 & 87 & 87 & 87 & 87 & 59 & 87 & 87 & 75 & 87 & 87 & 87 & 87 & 87 & 87 & 87 & 87 & 78 & 87 & 2010 & \\
\hline Toplam Diş Sayısı & 145 & 100 & 145 & 145 & 143 & 145 & 145 & 144 & 145 & 145 & 104 & 145 & 145 & 125 & 145 & 145 & 145 & 145 & 145 & 145 & 145 & 145 & 130 & 145 & 3356 & \\
\hline \multicolumn{27}{|l|}{ Sinıf 1} \\
\hline Erkek & 3 & 8 & 10 & 6 & 10 & 6 & 5 & 3 & 3 & 3 & 5 & 2 & 2 & 2 & 2 & 2 & 5 & 3 & 2 & 3 & 4 & 8 & 4 & 4 & 105 & \\
\hline Oran \% & 5,17 & 19,05 & 17,24 & 10,34 & 17,86 & 10,34 & 8,62 & 5,26 & 5,17 & 5,17 & 11,11 & 3,45 & 3,45 & 4,00 & 3,45 & 3,45 & 8,62 & 5,17 & 3,45 & 5,17 & 6,90 & 13,79 & 7,69 & 6,90 & 7,80 & $\mathrm{X}^{2} \mathrm{~F}=0,000$ \\
\hline KIz & 4 & 9 & 10 & 18 & 15 & 15 & 15 & 5 & 9 & 10 & 4 & 4 & 4 & 5 & 4 & 10 & 7 & 3 & 4 & 4 & 3 & 7 & 5 & 5 & 179 & \\
\hline Oran \% & 4,60 & 15,52 & 11,49 & 20,69 & 17,24 & 17,24 & 17,24 & 5,75 & 10,34 & 11,49 & 6,78 & 4,60 & 4,60 & 6,67 & 4,60 & 11,49 & 8,05 & 3,45 & 4,60 & 4,60 & 3,45 & 8,05 & 6,41 & 5,75 & 8,91 & $\mathrm{X}^{2} \mathrm{~F}=0,000$ \\
\hline Toplam & 7 & 17 & 20 & 24 & 25 & 21 & 20 & 8 & 12 & 13 & 9 & 6 & 6 & 7 & 6 & 12 & 12 & 6 & 6 & 7 & 7 & 15 & 9 & 9 & 284 & \\
\hline Oran $\%$ & 4,83 & 17,00 & 13,79 & 16,55 & 17,48 & 14,48 & 13,79 & 5,56 & 8,28 & 8,97 & 8,65 & 4,14 & 4,14 & 5,60 & 4,14 & 8,28 & 8,28 & 4,14 & 4,14 & 4,83 & 4,83 & 10,34 & 6,92 & 6,21 & 8,46 & $\mathrm{X}^{2} \mathrm{~F}=0,000$ \\
\hline \multicolumn{27}{|l|}{ Sinıf 2} \\
\hline Erkek & 4 & 4 & 21 & 39 & 32 & 30 & 31 & 35 & 31 & 21 & 6 & 3 & 3 & 30 & 25 & 20 & 10 & 8 & 6 & 19 & 22 & 27 & 20 & 3 & 450 & \\
\hline Oran \% & 6,90 & 9,52 & 36,21 & 67,24 & 57,14 & 51,72 & 53,45 & 61,40 & 53,45 & 36,21 & 13,33 & 5,17 & 5,17 & 60,00 & 43,10 & 34,48 & 17,24 & 13,79 & 10,34 & 32,76 & 37,93 & 46,55 & 38,46 & 5,17 & 33,43 & $\mathrm{X}^{\mathrm{z}} \mathrm{F}=0,000$ \\
\hline $\mathrm{K}_{12}$ & 5 & 11 & 25 & 48 & 47 & 40 & 36 & 55 & 48 & 25 & 15 & 5 & 4 & 25 & 47 & 45 & 18 & 13 & 11 & 30 & 38 & 45 & 30 & 4 & 670 & \\
\hline Oran \% & 5,75 & 18,97 & 28,74 & 55,17 & 54,02 & 45,98 & 41,38 & 63,22 & 55,17 & 28,74 & 25,42 & 5,75 & 4,60 & 33,33 & 54,02 & 51,72 & 20,69 & 14,94 & 12,64 & 34,48 & 43,68 & 51,72 & 38,46 & 4,60 & 33,33 & $\mathrm{X}^{2} \mathrm{~F}=0,000$ \\
\hline Toplam & 9 & 15 & 46 & 87 & 79 & 70 & 67 & 90 & 79 & 46 & 21 & 8 & 7 & 55 & 72 & 65 & 28 & 21 & 17 & 49 & 60 & 72 & 50 & 7 & 1120 & \\
\hline Oran \% & 6,21 & 15,00 & 31,72 & 60,00 & 55,24 & 48,28 & 46,21 & 62,50 & 54,48 & 31,72 & 20,19 & 5,52 & 4,83 & 44,00 & 49,66 & 44,83 & 19,31 & 14,48 & 11,72 & 33,79 & 41,38 & 49,66 & 38,46 & 4,83 & 33,37 & $\mathrm{X}^{2} \mathrm{~F}=0,000$ \\
\hline \multicolumn{27}{|l|}{ Sinıf 3} \\
\hline Erkek & 0 & 1 & 3 & 7 & 10 & 5 & 3 & 13 & 11 & 2 & 0 & 0 & 0 & 7 & 15 & 22 & 14 & 4 & 5 & 7 & 20 & 10 & 4 & 0 & 163 & \\
\hline Oran \% & 0,00 & 2,38 & 5,17 & 12,07 & 17,86 & 8,62 & 5,17 & 22,81 & 18,97 & 3,45 & 0,00 & 0,00 & 0,00 & 14,00 & 25,86 & 37,93 & 24,14 & 6,90 & 8,62 & 12,07 & 34,48 & 17,24 & 7,69 & 0,00 & 12,11 & $\mathrm{X}^{2} \mathrm{~F}=0,000$ \\
\hline$K_{1 z}$ & 0 & 2 & 5 & 8 & 20 & 7 & 6 & 19 & 15 & 0 & 0 & 0 & 0 & 14 & 20 & 25 & 10 & 4 & 5 & 3 & 20 & 15 & 4 & 0 & 202 & \\
\hline Oran \% & 0,00 & 3,45 & 5,75 & 9,20 & 22,99 & 8,05 & 6,90 & 21,84 & 17,24 & 0,00 & 0,00 & 0,00 & 0,00 & 18,67 & 22,99 & 28,74 & 11,49 & 4,60 & 5,75 & 3,45 & 22,99 & 17,24 & 5,13 & 0,00 & 10,05 & $\mathrm{X}^{2} \mathrm{~F}=0,000$ \\
\hline Toplam & 0 & 3 & 8 & 15 & 30 & 12 & 9 & 32 & 26 & 2 & 0 & 0 & 0 & 21 & 35 & 47 & 24 & 8 & 10 & 10 & 40 & 25 & 8 & 0 & 365 & \\
\hline Oran \% & 0,00 & 3,00 & 5,52 & 10,34 & 20,98 & 8,28 & 6,21 & 22,22 & 17,93 & 1,38 & 0,00 & 0,00 & 0,00 & 16,80 & 24,14 & 32,41 & 16,55 & 5,52 & 6,90 & 6,90 & 27,59 & 17,24 & 6,15 & 0,00 & 10,88 & $\mathrm{X}^{2} \mathrm{~F}=0,000$ \\
\hline
\end{tabular}

\section{TARTIŞMA}

Ağız ve dişlerin görünümü estetiğin değerlendirilmesinde oldukça önemlidir. Çünkü vücudun genelinde yüz bölgesi, yüz bölgesinde ise ağız ve dişler estetiği öne çıkaran bölgelerdir. ${ }^{13,14}$ Çocuklar üzerinde yapılan bir çalışmada boy, kilo ve saç görünümünden sonra diş görünümünün en büyük alay konusu olduğu belirlenmiştir. ${ }^{15}$ Ortodontik tedavi isteğinin sebebini belirlemeye yönelik yapılan bir çalışmada sırası ile dişlerin görünümünün (\% 84), diş hekimi tavsiyesinin (\% 52) ve yüz görünümünün (\% 41) etkili olduğu belirlenmiştir. ${ }^{16}$ Ortodonti kliniğine başvuran hastalar mümkün olduğunca düzgün sıralanmış dişlere ve estetik bir gülüşe sahip olmak istemektedirler. Dişlerinin görünümünün düzeltilmesi isteğinde olan hasta ve velileri için tedavinin dişler üzerinde estetik sorun teşkil eden lekeler bırakılarak bitirilmesi oldukça büyük hayal kırıklığı oluşturabilmektedir.

Sabit ortodontik tedavi sırasında, özellikle ağız hijyeninin yetersiz olduğu durumlarda karşımıza çıkan mine demineralizasyonunun istenmeyen bir yan etki olduğu bilinmektedir. ${ }^{17}$ Demineralizasyonun devamı ile çürük başlangıcı olan beyaz nokta lezyonlar (beyaz nokta lezyonlar) ortaya çıkarmaktadır.

Beyaz nokta lezyonların dağılımı belirlenirken birinci büyük azı dişinden itibaren etkilenen dişler çalışmaya dâhil edilmiştir. Tedavi gruplarının etkinliğinin değerlendirildiği kısımda küçük azı, köpek ve keser dişler değerlendirmeye alınmıştır. Büyük azı dişler de $90^{\circ}$ açıyla fotoğraf kaydı alımı zor olduğu ve birçok hastada sorunla karşılaştırılığı için değerlendirmeye dâhil edilmemiştir.
Genel olarak beyaz nokta lezyonların gösterilmesi, değerlendirilmesi, karşılaştıııması gibi durumlarda fotoğrafla kayıt yöntemi uzun yıllardır kullanılan ve pek çok araştırmacı tarafından kabul gören bir yöntemdir. ${ }^{18-21}$ Chapman ve ark, ${ }^{21}$ dijital fotoğraf makinesi ve görsel incelemenin arasında fark bulmamışlardır. Birkaç tane gözden kaçan lezyonu daha sonra fotoğraf incelemesi sırasında tespit etmişler bunun da önemsiz derecede olduğunu belirtmişlerdir. Bizde çalışmamızda bu sebepten fotoğraf kaydı alınması yöntemini kullandık.

Gorelick ve ark, ${ }^{4}$ 50'si kontrol, 121 'si ortodontik tedavisi bitirilmiş toplam 171 hasta üzerinde yaptığı çalışmada, kontrol grubunda \% 24 hastada en az bir diş ortodontik tedavi kaynaklı beyaz nokta lezyon oluşan bölgede gelişimsel olmayan lezyona rastlanmıştır. Dişlere göre dağılımı \% 3,6 olarak tespit edilmiştir. Test grubunda ise 121 hastadan 60 (\% $49,6)$ tanesi diş sayısı olarak ta \% 10,8 oranında etkilenme tespit etmişlerdir. Yine aynı çalışmada en yoğun beyaz nokta lezyon bölgesi olarak üst çene ön bölgesi $(\% 15,3)$ ile alt çene arka bölgesi $(\% 14,1)$ ve en az olarak üst çene arka bölgesi $(\% 4,5)$ olarak tespit etmişlerdir. Hem üst çenede hem de alt çenede sağ sol taraflar arasında fark bulunmamıştır. En fazla etkilenen diş olarak üst çene yan keser dişler olarak tespit edilmiştir. Bizim çalışmamızda da bu çalışma ile uyumlu olarak üst sağ yan keser diş (toplam \% $93,7)$ en çok etkilenen diş olarak tespit edilmiştir.

Bunun tersine en çok etkilenen dişlerin alt köpek dişleri olduğunu daha sonra üst yan keser dişlerinin geldiğini tespit eden araştırmacılarda vardır. $\mathrm{Bu}$ çalışmalarda bu bölgenin temizlenmesinin daha zor olduğu, sağ sol el değişim bölgesi olduğu için plak 


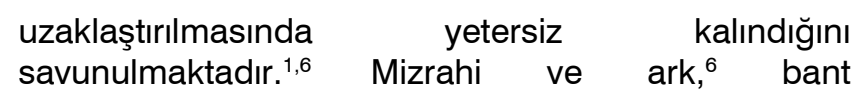
uygulamasından dolayı üst ve alt çenedeki büyük azı dişlerin en fazla etkilendiğini belirtmektedir. Dişler arasında beyaz nokta lezyon dağılımları arasında fark olmadığını belirten araştırmacılarda vardır. ${ }^{22}$

Araştırmamızda estetik olarak önemli görülen üst yan keser ve üst köpek dişleri en çok etkilenen dişlerdir. $\mathrm{Bu}$ bulgularımı Artun ve Brobakken, ${ }^{11}$ Ogaard, ${ }^{9}$ Chapman ve ark $^{21}$ 'nın bulguları ile desteklenmektedir. Üst yan keser ve üst köpek dişlerinin daha çok etkilenmesi estetik kaygıyı da artırmaktadır. Bundan dolayı beyaz nokta lezyonlar tedavi edilmesi oldukça önemlidir.

\section{SONUÇ}

Bireylere ait olan 3356 adet diş incelenmiş ve 1796 adet dişin etkilenmiş olduğu tespit edilmiştir.

Beyaz nokta lezyon dağılımı arasında kızlar ve erkekler arasında dağılım farkı gözlenmemiştir.

En fazla etkilenen diş olarak üst çenede yan keser dişler olarak tespit edilmiştir. Üst yan keser dişleri üst köpek dişleri, alt köpek dişleri ve alt birinci küçük azı dişleri takip etmiştir. 


\section{KAYNAKLAR}

1. Zachrisson BU, Zachrisson S. Caries incidence and oral hygiene during orthodontic treatment. Scand $\mathrm{J}$ Dent Res 1971;79(6):394-401.

2. Gwinnett AJ, Ceen RF. Plaque distribution on bonded brackets: a scanning microscopic study. Am J Orthod. 1979;75(6):667-77.

3. O'Reilly MM, Featherstone JD: Demineralization and remineralization around orthodontic appliances: an in vivo study. Am J Orthod Dentofacial Orthop. 1987;92(1):33-40.

4. Gorelick L, Geiger AM, Gwinnett AJ. Incidence of white spot formation after bonding and banding. Am J Orthod 1982;81(2):93-8.

5. Rosenbloom RG, Titanoff N. Salivary streptococcus mutans levels in patients before, during, and after orthodontic treatment. Am J Orthod Dentofacial Orthop. 1991;100(1):35-7

6. Mizrahi E. Enamel demineralization following orthodontic treatment. Am J Orthod. 1982;82(1):62- 7.

7. Ogaard B, Rolla G, Arends J. Orthodontic appliances and enamel demineralization. Am $\mathrm{J}$ Orthod Dentofacial Orthop 1988;94(1):68-73.

8. Millet DT, Nunn JH, Welbury RR, Gordon PH. Decalcification in relation to brackets bonded with glass ionomer cement or a resin adhesive. Angle Orthod. 1999;69(1):65-70.

9. Ogaard B. Prevalence of white spot lesions in 19-yearolds: a study on untreated and orthodontically treated persons 5 years after treatment. Am J Orthod Dentofacial Orthop. 1989;96(5):423-7.

10.Zachrisson BU, Heimgard E, Ruyter IE, Mjur IA. Problems with sealants for bracket bonding. American Journal of Orthodontics 1979;75(6):641-9.

11.Artun J, Brobakken BO. Prevalence of carious white spots after orthodontic treatment with multibanded appliances. Eur J Orthod 1986;8(4):229-331.

12. Curzon ME, Spector PC. Enamel mottling in a high strontium area of the U.S.A. Community. Dent Oral Epidemiol. 1977;5(5):243-7.

13. Lucker GW, Graber LW, Pietromonaco P. The importance of dentofacial appearance in facial esthetics. A signal detection approach. Basic appl soc psychol. 1981;2(4):261-74.

14. Mueser KT, Grau BW, Susman S, Rosen AJ. Yoy're only as pretty as you feel: Facial expression as a determinant of physical attractiveness. J Pers Soc Psychol. 1984;46(2):469-78.

15.Shaw WC, Meek SC, Jones DS. Nicknames, teasing, harassment and the salience of dental eatures among school children. Br J Orthod. 1980;7(2):75-80.

16.Dann C, Philips C, Broder HL, Tulloch JF. Selfconcept, class II malocclusion, and early treatment. Angle Orthod. 1995;65(6):411-6.
17. Mitchell $L$. An investigation into the effect of a fluoride releasing adhesive on the prevalence of enamel surface changes associated with directly bonded orthodontic attachments. $\mathrm{Br} \mathrm{J}$ Orthod 1992;19(3):207-14.

18. Willmot DR: White lesions after orthodontic treatment: does low fluoride make a difference? J Orthod 2004;31(3):233-40.

19. Benson PE, Shah AA, Millett DT, Dyer F, Parkin N, Vine RS. Fluorides, orthodontics and demineralization: a systematic review. J Orthod 2005;32(2):102-14.

20.Murphy TC, Willmot DR, Rodd HD: Management of postorthodontic demineralized white lesions with microabrasion: A quantitative assessment. Am J Orthod Dentofacial Orthop. 2007;131(1):2733

21.Chapman JA, Roberts WE, Eckert GJ, Kula KS, Gonzalez-Cabezase C. Risk factors for incidence and severity of White spot lesions during treatment with fixed orthodontic appliances. Am J Orthod Dentofacial Orthop. 2010;138(2):188-94.

22. Tufekci E, Dixon JS, Gunsolley JC, Lindauerd SJ. Prevalence of white spot lesions during orthodontic treatment with fixed appliances. Angle Orthod. 2011;81(2):206-10.

\footnotetext{
Yazışma Adresi:

Mehmet AKIN

Alanya Alaaddin Keykubat Üniversitesi

Diş Hekimliği Fakültesi

Ortodonti $A D$,

Alanya, Antalya, Türkiye

Tel : +902425106140

E Posta: mehmet.akin@alanya.edu.tr
} 